\title{
EFFECT OF AUTOXIDIZED METHYL LINOLEATE ON GLUTATHIONE PEROXIDASE
}

\author{
Hironori Negishi, Kenshiro FuJimoto, \\ and Takashi KANEDA ${ }^{1}$ \\ Laboratory of Food Science, Department of Food Chemistry, \\ Faculty of Agriculture, Tohoku University, \\ 1-1 Amamiyamachi-Tsutsumidori, Sendai 980, Japan
}

(Received February 18, 1980)

Summary To determine the effect of several oxidation stages of autoxidized methyl linoleate (AOML) on glutathione peroxidase (GSH$\mathrm{Px}$ ), several experiments were carried out. In the first experiment, GSHPx was prepared from gastrointestinal tract and liver which were excised from mice, and the effects of AOML rich in hydroperoxides (HP) and that rich in the decomposition products of HP on the activity of GSH-Px were compared. The results indicate that GSH-Px indiscriminately metabolized both types of AOML without strict recognition of the specificity of the substrate. In the second experiment, it was noted that the inhibitory rate of GSH-Px by in vitro incubation with various AOML closely correlated with POV of the sample esters, but did not correspond with the toxicity revealed by intraperitoneal injection or intragastric feeding. In the next experiment, mice were given AOML with a low vitamin $\mathrm{E}$ diet for 45 days, and an increase of GSH-Px activity in gastrointestinal tract in proportion to the POV of the administered oil occurred, but the level in liver remained unchanged. On the contrary, the increase of GSH-Px activity by intraperitoneal injection of AOML in mice was marked in liver, but not in gastrointestinal tract. From these results, most of the orally administered AOML seemed to be reduced in the mucosa of the gastrointestinal tract. However, the marked increase of fluorescence in the lipid fraction of heart and kidney by oral administration of AOML suggested that the damage caused by it was not limited to gastrointestinal tract, but was spread through the whole body.

Keywords glutathione peroxidase, autoxidation, methyl linoleate, vitamin E, hydroperoxide, hydroperoxyalkenal, selenium, fluorescence of peroxidized lipids

Many papers have been published on the toxicity of lipid peroxides, and it is known that autoxidized unsaturated oils cause serious damage to animals (1-7),

1 根岸弘典, 藤本健四郎, 金田尚志 
such as inhibition of enzymes $(8,9)$. Among the various oxidation products, Yoshioka and Kaneda $(10,11)$ reported that the decomposition products of hydroperoxides, such as hydroperoxyalkenals containing 5-9 carbon atoms, showed a market toxicity in mice.

Glutathione peroxidase (glutathione: hydrogen peroxide oxidoreductase, EC 1.11.1.9) is known to be an important enzyme for the prevention of endogenous formation of lipid peroxide in cell membrane $(12,13)$. Glutathione peroxidase (GSH-Px), an intracellular enzyme that utilizes lipid peroxide as a substrate $(14,15)$, was demonstrated in rat liver $(9)$ and other organs. As this enzyme is known to exist in the gastrointestinal tract, it might be responsible for the detoxication of dietary hydroperoxides.

Reddy and Tappel (16) showed that in rats without the supplementation of selenium, GSH-Px activity was significantly increased in the group fed autoxidized corn oil. Draper et al. (17) reported that the feeding of oxidized corn oil inadequate in selenium and vitamin $\mathrm{E}$ increased the specific activity of GSH-Px in stomach mucosa.

The present study was designed to elucidate the protective mechanisms of organisms from exogenous peroxides. We examined the specificity of GSH-Px on various oxidative products in autoxidized methyl linoleate (ML), including hydroperoxides and their decomposition products. The inactivation rate of GSH$\mathrm{Px}$ with these oxidative products were examined next. The change of GSH-Px activities in several organs after the feeding or the intraperitoneal injection of autoxidized oil was also determined.

\section{EXPERIMENTAL}

Autoxidized methyl linoleate. ML was prepared from safflower oil mixed fatty acid esters by the method of urea adduction and successive distillation under reduced pressure. The purity of ML was $90 \%$ as examined by GLC, with most of the impurity being methyl oleate.

ML was autoxidized under two different conditions. In the first experiment, autoxidation of $\mathrm{ML}$ was carried out at $60^{\circ} \mathrm{C}$ by passing oxygen through it. When the peroxide value (POV) reached a maximum, portions of the ester were sampled and called AOML-A1. After $57 \mathrm{hr}$, POV declined, and autoxidized esters were sampled and called AOML-A2. Further, AOML-A2 was subjected to molecular distillation and fractionated into low molecular weight distillate, monomer, and dimer fractions. Low molecular weight distillate was collected in dry ice-acetone coolant.

In the second experiment, autoxidation of ML was carried out at $40^{\circ} \mathrm{C}$. As in the first experiment, esters with the maximum POV (10 days) and esters with the decreased POV (28 days) were sampled and called AOML-B1 and AOML-B2, respectively.

We also prepared autoxidized methyl linoleate rich in hydroperoxide (MLHP). To prepare the MLHP, ML was autoxidized at $4^{\circ} \mathrm{C}$ for 26 days by 
passing dry air through it, and MLHP was concentrated by dry column chromatography.

Preparation of GSH-Px. Two methods according to Tappel et al.(18) and Hayashi et al. (19) were employed with some modification for the preparation of GSH-Px. In the first method, homogenized mouse organs were centrifuged at $12,000 \times g$ for $20 \mathrm{~min}$. The supernatant solution was subjected to an acid treatment by addition of reduced glutathione to a final concentration of $5 \mathrm{~mm}$, and $\mathrm{pH}$ was adjusted to 5.0. After incubation for an hour at $4{ }^{\circ} \mathrm{C}$, the solution was centrifuged at $12,000 \times g$ for $20 \mathrm{~min}$. The supernatant portion was neutralized, and this solution was used as enzyme solution A. In the second method, the homogenized mouse organs were centrifuged at $8,500 \times g$ for $15 \mathrm{~min}$. Then the supernatant was centrifuged at $105,000 \times g$ for $60 \mathrm{~min}$, and this supernatant was named enzyme solution B.

Assay of GSH-Px activity. The enzyme assay was carried out according to the method of Little et al. (20) with some modification. The enzyme was coupled to NADPH via glutathione reductase, and GSH-Px activity was determined by the amount of oxidized NADPH which was measured spectrophotometrically at $340 \mathrm{~nm}$. The standard reaction mixture consisted of $0.25 \mathrm{~mm}$ reduced glutathione, $0.20 \mathrm{~mm}$ cumene hydroperoxide, $0.12 \mathrm{~mm}$ NADPH, $0.1 \mu \mathrm{g}$ of glutathione reductase, $0.091 \mathrm{~mm}$ EDTA, and $50 \mathrm{~mm}$ Tris buffer $(\mathrm{pH} 7.6)$. The reaction was initiated by addition of cumene hydroperoxide to the mixture and incubated at $37^{\circ} \mathrm{C}$ for 15 min. Protein was assayed by the method of Miller (21). The enzyme activity was expressed as $\mu \mathrm{mol}$ NADPH oxidized $/ 15 \mathrm{~min} / \mathrm{mg}$ protein. Student's $t$-test was used to determine the significance of the difference between mean values.

Efficiency of various preparations of AOML as substrate of GSH-Px. Enzyme solution A was used in this experiment. Each autoxidized oil was emulsified in the same concentration of cumene hydroperoxide as was used for the control. Then the enzyme activity was assayed for each reaction mixture to compare which kinds of peroxides in the autoxidized ester were reduced well.

Preincubation system to measure the inhibitory effect of AOML on GSH$P x$. Enzyme solutions B from several organs of 4 mice were emulsified with AOML-B1 or B2, by a sonicator, and incubated at $25^{\circ} \mathrm{C}$ for $1 \mathrm{hr}$ in advance of the enzyme assay.

Effect of dietary AOML on GSH-Px activity. For 45 days, 4 groups of 3 male $\mathrm{ddY}$ mice $^{2}$ were fed the basal diet with a low vitamin $\mathrm{E}$ level ad libitum, and $0.1 \mathrm{ml}$ of the following test oils were administered orally every other day. Group I is the control group, and mice were fed lard fatty acid methyl esters (LFME) containing $5 \%$ of ML. The group II diet contained $10 \%$ ML. The diet of Group III, the AOML-B1 group, consisted of LFME containing $5 \%$ of AOML-B1. That of Group IV, the AOML-B2 group, consisted of LFME containing $5 \%$ of AOML-B2. The basal diet contained the following percentages of nutrients: corn starch, 40;

${ }^{2}$ Funabashi Farm Co., Inc., Funabashi, Chiba.

Vol. 26, No. 3, 1980 
vitamin $\mathrm{E}$ free casein, 27; $\alpha$-starch, 11; cellulose powder, 9; salt mixture, 6; sucrose, 5 ; vitamin mixture, 2. Selenium concentration was less than $0.05 \mathrm{ppm}$. After 45 days, mice were killed, and liver, stomach, small intestine, cecum and large intestine were excized immediately, and the GSH-Px activity was assayed.

Measurement of fluorescent lipid peroxidation products in tissues. Fluorescence of heart and kidney lipids were measured after 45 days on the experimental diets. Lipids were extracted with chloroform-methanol, and the fluorescence measurement was carried out according to the method of Tappel et al. (22).

Effect of intraperitoneally injected AOML. Three groups of 6 mice were intraperitoneally injected with $0.15 \mathrm{ml}$ of $\mathrm{ML}$, ML containing $10 \mathrm{mg}$ of AOML-B1, and ML containing $10 \mathrm{mg}$ of AOML-B2. Twenty hours after injection, gastrointestinal tract and liver tissues were assayed for the GSH-Px activity.

\section{RESULTS AND DISCUSSION}

\section{Chemical characteristics of sample oils}

Chemical characteristics of the sample oils are presented in Table 1. Comparing AOML-A1 and A2, POV of A1 was higher than that of A2, indicating that A1 was rich in hydroperoxides. Sample B1 showed a relatively low carbonyl value (COV), compared with A1 and B2. The LMWD fraction was composed of low molecular weight compounds such as aldehydes and hydroperoxyalkenals. The monomer fraction contained intact ML, its hydroperoxides and low molecular compounds, judging from the mean molecular weight. The mean molecular weight of the dimer fraction was higher than that of the original AOML-A2, but its value did not reach 600 , the theoretical value of the $\mathrm{ML}$ dimer, so it seemed to contain nonvolatile monomers, such as hydroxy compounds, besides dimers.

Table 1. Chemical characteristics of autoxidized oils.

\begin{tabular}{lccc}
\hline & POV & COV & MMW $^{\mathrm{a}}$ \\
\hline AOML-A1 & 2,570 & 1,320 & 353 \\
AOML-A2 & 1,660 & 1,390 & 412 \\
MLHPO & 4,050 & - & 310 \\
AOML-A2 & 1,750 & 4,110 & 254 \\
$\quad$ LMWD & 1,390 & 217 \\
$\quad$ fr. & 2,050 & 1,250 & 438 \\
$\quad$ Dimer fr. & 1,640 & 700 & 344 \\
AOML-B1 & 2,200 & 1,700 & 490 \\
AOML-B2 & 1,200 & & \\
\hline
\end{tabular}

\footnotetext{
a Mean molecular weight. ${ }^{b}$ Low molecular weight distillate.
} 
Efficiency of various preparations of AOML as the substrate of GSH-PX.

Figure 1 shows the effect of various preparations of AOML on GSH-Px as substrate. It was ascertained that GSH-Px catabolized all kinds of peroxides, and a strict specificity for substrate was not noted. The LMWD fraction which showed the greatest toxicity by oral administration (10) was also catabolized. No difference in specificity that could be derived from the origin of the enzyme was found either.

Inhibitory effect of AOML on GSH-Px

The inhibitory effect of AOML on GSH-Px is presented in Table 2. By
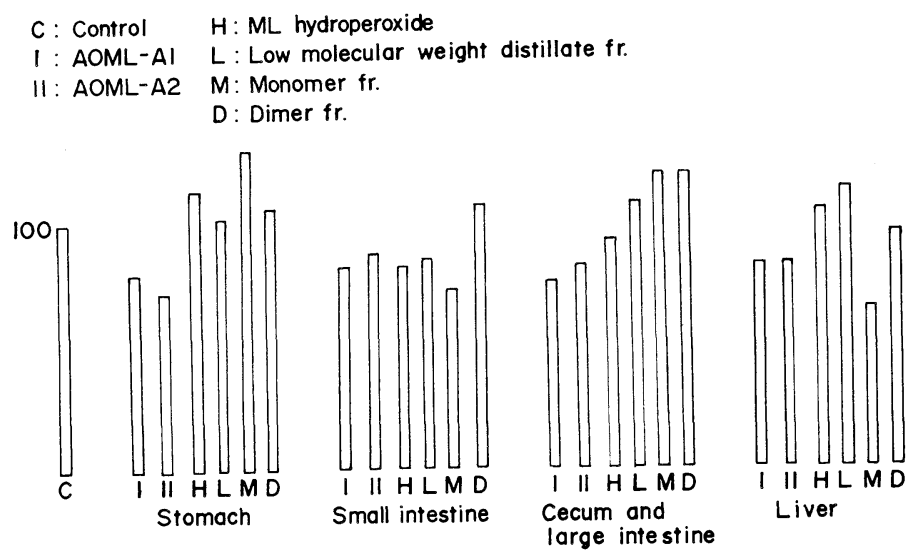

Fig. 1. Effect of autoxidized oils on GSH-Px activity in the GI tract and liver.

Table 2. Inhibitory effects of autoxidized oils on GSH-Px activity in the intestinal tract and liver in vitro.

\begin{tabular}{|c|c|c|c|c|c|c|}
\hline \multirow{2}{*}{ Organ } & \multirow{2}{*}{ Control } & \multicolumn{2}{|c|}{ Preincubation group ${ }^{* 1}$} & \multicolumn{3}{|c|}{ Statistical significance*2 } \\
\hline & & AOML-B1 & AOML-B2 & & & \\
\hline & $\mu \mathrm{mol}$ of $\mathrm{NAD}$ & oxidized $/ 15$ & $\mathrm{in} / \mathrm{mg}$ protein $* 3$ & $p^{\mathrm{a}}$ & $p^{\mathrm{b}}$ & $p^{\mathrm{c}}$ \\
\hline Small intestine & $445 \pm 52$ & $191 \pm 28$ & $460 \pm 64$ & $<0.02$ & $<0.02$ & $\mathrm{NS}^{* 4}$ \\
\hline $\begin{array}{l}\text { Cecum + large } \\
\text { intestine }\end{array}$ & $318 \pm 63$ & $192 \pm 52$ & $338 \pm 98$ & NS & NS & NS \\
\hline Liver & $1,734 \pm 110$ & $732 \pm 98$ & $1,030 \pm 414$ & $<0.01$ & NS & NS \\
\hline
\end{tabular}

${ }^{* 1}$ Four mice per group. ${ }^{* 2}$ Comparisons for significant differences are between groups;

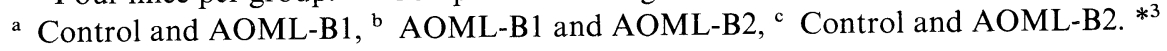
Mean \pm SD. ${ }^{* 4}$ NS (not significant), $p<0.05$. 
incubating GSH-Px with AOML, especially in the case of AOML-B1, GSH-Px was inactivated markedly. No inhibition by $\mathrm{B} 2$ (which showed the most severe toxicity) was observed. The hinderance rate of GSH-Px with autoxidized oils seemed to be proportional to the amounts of peroxides in the autoxidized oils.

\section{Effect of dietary AOML on the GSH-Px level of various organs}

Table 3 shows the effect of oral administration of AOML on GSH-Px activity. On the 45th day, the enzyme activity in the gastrointestinal (GI) tract increased in AOML-B1. Comparing the GSH-Px activities of the B1 and B2 groups, B1 tended to increase in activity. As the content of hydroperoxides was higher in the B1 oil, and, on the contrary, the secondary decomposition products were in a low concentration in $\mathrm{B} 1$, it seems that the increasing activity of GSH-Px in the GI tract was mainly related to the quantity of administered peroxides. The influence of secondary decomposition products which contained highly toxic hydroperoxyalkenals and various compounds $(10,11)$ was not significant. Although GSH-Px was induced in GI tract, no significant effect of autoxidized oil on GSH-Px activity was observed in liver. These results indicate that most of the administered peroxides were reduced by the GI tract membrane $(5,23,24)$, but as feeding peroxides to rats leads to appreciable concentrations in tissues $(2,25)$, a small amount of these peroxides and their degradation products would be carried through the lymphatics to the liver. We expected that if a large amount of polyunsaturated oil was fed, GSH-Px activity might be increased, but the difference of enzyme activity between the control and ML groups was not significant. The selenium concentrations of small intestine in control, AOML-B1, and AOML-B2 groups were 1.24, 1.25, $1.30 \mathrm{ppm}$, respectively.

Table 3. Effect of dietary autoxidized oils on GSH-Px activity in the GI tract and liver of mouse on the 45th day.

\begin{tabular}{|c|c|c|c|c|c|c|c|c|}
\hline \multirow{2}{*}{ Organ } & \multicolumn{4}{|c|}{ Dietary group*1 } & \multirow{2}{*}{\multicolumn{4}{|c|}{ Statistical significance $* 2$}} \\
\hline & Control & ML & AOML-B1 & AOML-B2 & & & & \\
\hline & $\mu \mathrm{mol}$ of $\mathrm{NA}$ & DPH oxidi & $\mathrm{zed} / 15 \mathrm{~min} / \mathrm{n}$ & g protein*3 & $p^{\text {a }}$ & $p^{\mathrm{b}}$ & $p^{\mathrm{c}}$ & \\
\hline Stomach & $220 \pm 60$ & $227 \pm 22$ & $590 \pm 90$ & $360 \pm 61$ & $<0.05$ & NS*4 & NS & \\
\hline Small intestine & $487 \pm 127$ & $293 \pm 14$ & $900 \pm 89$ & $527 \pm 116$ & $<0.10$ & $<0.10$ & NS & \\
\hline $\begin{array}{l}\text { Cecum + large } \\
\text { intestine }\end{array}$ & $290 \pm 49$ & $257 \pm 20$ & $623 \pm 22$ & $427 \pm 14$ & $<0.01$ & $<0.01$ & $<0.10$ & \\
\hline Liver & $1,553 \pm 165$ & $1,657 \pm 255$ & $1,900 \pm 816$ & $1,527 \pm 404$ & NS & NS & NS & \\
\hline
\end{tabular}

${ }^{* 1}$ Three mice per group. ${ }^{* 2}$ Comparisons for significant differences are between groups;

${ }^{\mathrm{a}}$ Control and AOML-B1, b AOML-B1 and AOML-B2, ${ }^{\mathrm{c}}$ Control and AOML-B2, ${ }^{\mathrm{d}}$ Control and ML. ${ }^{* 3}$ Mean \pm SD. ${ }^{* 4}$ NS (not significant), $p<0.10$. 


\section{Measurement of fluorescent lipid peroxidation products in tissues}

As shown in Fig. 2, the fluorescence of heart and kidney lipids was measured after 45 days of feeding autoxidized oils. The fluorescence in both heart and kidney was increased considerably by the administration of autoxidized oils. This result suggests that the autoxidized oil was mostly decomposed by the GI mucosa, and the amount of peroxides absorbed through the mucosa was presumed to be very small as mentioned above, but the damage by peroxy lipids was extended to various organs such as heart and kidney. Judging from the fluorescence intensity, damage of the tissues by administration of AOML-B2 was almost equal to or slightly more severe than that of B1, and did not agree with the rate of GSH-Px induction. Fluorescence of the ML group was higher than that of the control group, and so it was considered that the damage derived from endogenous peroxidation would be caused by the feeding of a large amount of methyl linoleate, in spite of a lack of increase of the GSH-Px activity.

Effect of intraperitoneally injected AOML on the GSH-Px level of several organs

The effects of intraperitoneally injected autoxidized oils on the GSH-Px activities of the GI tract and liver are presented in Table 4. The most characteristic change in the AOML-B1 injected group was the increase of GSH-Px in liver, which was not found with oral administration. However, in the case of the B2 group, the GSH-Px activity in liver was not changed compared with the control group. These results indicate that the increase of GSH-Px activity by intraperitoneal injection of the autoxidized oil was proportional to the amount of peroxides in the injected oil, as recognized in oral administration. With the oral administration of the autoxidized oil in mice, GSH-Px activities in all parts of the GI tract increased, but the GSH-Px activity in liver did not increase significantly. From these results, we

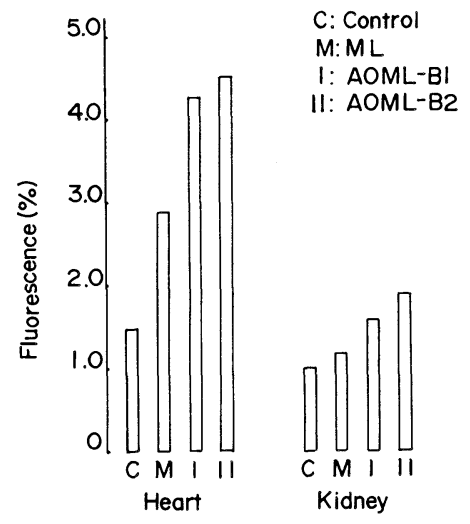

Fig. 2. Effect of dietary autoxidized oils on the fluorescence of mouse heart and kidney. 
Table 4. Effect of intraperitoneally injected autoxidized oils on GSH-Px activity in the GI tract and liver of mouse.

\begin{tabular}{|c|c|c|c|c|c|c|}
\hline \multirow{2}{*}{ Organ } & \multicolumn{3}{|c|}{ Injection group*1 } & \multicolumn{3}{|c|}{ Statistical significance*2 } \\
\hline & Control (ML) & AOML-B1 & AOML-B2 & & & \\
\hline & $\mu \mathrm{mol}$ of $\mathrm{NADF}$ & oxidized/1 & in $/ \mathrm{mg}$ prote & ${ }^{* 3} p^{\mathrm{a}}$ & $p^{\mathrm{b}}$ & $p^{\mathrm{c}}$ \\
\hline Stomach & $310 \pm 47$ & $365 \pm 48$ & $390 \pm 66$ & NS*4 & NS & NS \\
\hline Small intestine & $660 \pm 141$ & $665 \pm 101$ & $770 \pm 136$ & NS & NS & NS \\
\hline $\begin{array}{l}\text { Cecum }+ \text { large } \\
\text { intestine }\end{array}$ & $510 \pm 100$ & $640 \pm 39$ & $615 \pm 135$ & NS & NS & NS \\
\hline Liver & $1,970 \pm 178$ & $2,840 \pm 286$ & $1,930 \pm 205$ & $<0.05$ & $<0.05$ & NS \\
\hline
\end{tabular}

*1 Six mice per group. *2 Comparisons for significant differences are between groups;

${ }^{\text {a }}$ Control and AOML-B1, ${ }^{\mathrm{b}}$ AOML-B2, ${ }^{\mathrm{c}}$ Control and AOML-B2. ${ }^{* 3}$ Mean \pm SD. ${ }^{* 4}$ NS (not significant), $p<0.05$.

considered that when the peroxy lipids reach the liver by intraperitoneal injection, the GSH-Px activity in liver is induced considerably, but in the case of oral administration, no change was observed in liver GSH-Px activity, because most of the peroxides may be reduced in the GI tract.

\section{Conclusion}

GSH-Px prepared from mouse GI tract and liver catalyze the reduction of various types of autoxidized oils, but a strict specificity of substrate was not recognized. By oral administration of autoxidized oils to mice, the induction of GSH-Px observed was in proportion to the amount of administered peroxides; however, it was limited to the GI tract, and no change in liver was observed. On the contrary, by intraperitoneal injection, the induction of liver GSH-Px was remarkable, suggesting that the orally administered autoxidized oil was mainly reduced by the GI mucosa. Moreover, we noted an increase of fluorescence, which indicates peroxy damage, was found in both heart and kidney, and the influence of administration was not limited to the GI tract as it extended to the whole body.

\section{REFERENCES}

1) Kaneda, T., and Ishii, S. (1954): Nutritive value or toxicity of highly unsaturated fatty acids. I. J. Biochem. (Tokyo), 41, 327-335.

2) Kaneda, T., Sakai, H., and Ishii, S. (1955): Nutritive value or toxicity of highly unsaturated fatty acids. II. J. Biochem. (Tokyo), 42, 561-573.

3) Horgan, V. J., Philpot, J. St. L., Porter, B. W., and Roodyn, D. B. (1957): Toxicity of autoxidized squalene and linoleic acid, and of simpler peroxides, in relation to toxicity of radiation. Biochem. J., 67, 551-558. 
4) Holman, R. T., and Greenberg, S. I. (1958): A note on the toxicities of methyl oleate and ethyl linoleate peroxide. J. Am. Oil Chem. Soc., 35, 707.

5) Andrews, J. S., Griffith, W. H., Mead, J. F., and Stein, R. A. (1960): Toxicity of airoxidized soybean oil. J. Nutr., 70, 199-210.

6) Olcott, H. S., and Dolev, A. (1963): Toxicity of fatty acid ester hydroperoxides. Proc. Soc. Exp. Biol. Med., 114, 820-822.

7) Privett, O. S., and Cortesi, R. (1972): Observations on the role of vitamin E in the toxicity of oxidized fats. Lipids, 7, 780-787.

8) O'Brien, P. J., and Frazer, A. C. (1966): The effect of lipid peroxides on the biochemical constituents of the cell. Proc. Nutr. Soc., 25, 9-18.

9) Little, C., and O'Brien, P. J. (1968): An intracellular GSH-peroxidase with a lipid peroxide substrate. Biochem. Biophys. Res. Commun., 31, 145-150.

10) Yoshioka, M., and Kaneda, T. (1972): Studies on the toxicity of the autoxidized oils. I. The fractionation of the toxic compound and its identification. Yukagaku (in Japanese), 21, 316-321.

11) Yoshioka, M., and Kaneda, T. (1974): Studies on the toxicity of the autoxidized oils. III. The toxicity of hydroperoxyalkenals. Yukagaku (in Japanese), 23, 321-326.

12) Christophersen, B. O. (1968): The inhibitory effect of reduced glutathione on the lipid peroxidation of the microsomal fraction and mitochondria. Biochem. J., 106, 515-522.

13) Flohé, L., and Zimmermann, R. (1970): The role of GSH peroxidase in protecting the membrane of rat liver mitochondria. Biochim. Biophys. Acta, 223, 210-213.

14) Christophersen, B. O. (1968): Formation of monohydroxypolyenic fatty acids from lipid peroxides by a glutathione peroxidase. Biochim. Biophys. Acta, 164, 35-46.

15) Christophersen, B. O. (1969): Reduction of linolenic acid hydroperoxide by a glutathione peroxidase. Biochim. Biophys. Acta, 176, 463-470.

16) Reddy, K., and Tappel, A. L. (1974): Effect of dietary selenium and autoxidized lipids on the glutathione peroxidase system of gastrointestinal tract and other tissues in the rat. J. Nutr., 104, 1069-1078.

17) Vilas, N. N., Bell, R. R., and Draper, H. H. (1976): Influence of dietary peroxides, selenium and vitamin $\mathrm{E}$ on glutathione peroxidase of the gastrointestinal tract. $J$. Nutr., 106, 589-596.

18) Chiu, D. T. Y., Stults, F. H., and Tappel, A. L. (1976): Purification and properties of rat lung soluble glutathione peroxidase. Biochim. Biophys. Acta, 445, 558-566.

19) Nakamura, W., Hosoda, S., and Hayashi, K. (1974): Purification and properties of rat liver glutathione peroxidase. Biochim. Biophys. Acta, 358, 251-261.

20) Little, C., Olinescu, R., Reid, K. G., and O'Brien, P. J. (1970): Properties and regulation of glutathione peroxidase. J. Biol. Chem., 245, 3632-3636.

21) Miller, G. L. (1959): Protein determination for large numbers of samples. Anal. Chem., 31, 964.

22) Fletcher, B. L., Dillard, C. J., and Tappel A. L. (1973): Measurement of fluorescent lipid peroxidation products in biological systems and tissues. Anal. Biochem., 52, 1-9.

23) Glavind, J., and Tryding, N. (1960): On the digestion and absorption of lipoperoxides. Acta Physiol. Scand., 49, 97-102.

24) Glavind, J., and Slyven, C. (1970): Intestinal absorption and lymphatic transport of methyl linoleate hydroperoxide and hydroxyoctadecadienoate in the rat. Acta Chem. Scand., 24, 3723-3728.

25) Bunyan, J., Green, J., Murrell, E. A., Diplock, A. T., and Cawthorne, M. A. (1968): On the postulated peroxidation of unsaturated lipids in the tissues of vitamin E deficient rats. Br. J. Nutr., 22, 97-110.

Vol. 26, No. 3, 1980 